\title{
O DESENVOLVIMENTO DE PROGRAMA DE APOIO AOS MICRO E PEQUENOS EMPRESÁRIOS DA PERIFERIA DAS CIDADES DE ABRANGÊNCIA DA AMIC
}

\author{
The development of a support program to micro and small \\ entrepreneurs in the cities' suburbs inside AMIC scope
}

\section{El desarrollo de un programa de apoyo a micro y pequeños empresarios en los suburbios de las ciudades dentro del alcance AMIC}

\author{
Bruna Grascyela Schaefer Paese ${ }^{1}$ \\ Douglas Antoniazi² \\ Geysler Rogis Flor Bertolini ${ }^{3}$ \\ Jonny Christian Model ${ }^{4}$ \\ Kelvin Correa $\mathrm{Li}^{5}$ \\ Selmo José Bonatto ${ }^{6}$
}

\begin{abstract}
RESUMO
O presente artigo tem como objetivo identificar o perfil dos empresários associados da AMIC - Associação de Micro e Pequenas Empresas de Cascavel, enfatizando as formas com que esses empresários trabalham com a administração financeira em suas empresas. Foram utilizados como amostra 20 empresários associados da AMIC, participantes do projeto "O Desenvolvimento de Programa de Apoio aos Micro e Pequenos Empresários da Periferia das Cidades de Abrangência da AMIC" que contempla o programa Universidade Sem Fronteiras: Extensão Tecnológica Empresarial, desenvolvido nas salas de aula da UNIOESTE - Campus Cascavel. Os dados foram coletados através de visitas in loco, entrevistas nas empresas e aplicação de questionários. Verificou-se que os empresários, em sua maioria, têm pouco ou nenhuma forma de controle financeiro, como estoque ou fluxo de caixa. Em geral, têm uma escolaridade média e já estão a um bom tempo no mercado.

Palavras-chave: administração financeira; empreendimento; educação; tecnologia; micro e pequena empresa.
\end{abstract}

\begin{abstract}
This article aims to identify the profile of the business associates of AMIC - Micro and Small Companies Association of Cascavel, emphasizing the ways which these entrepreneurs work with financial management in their companies. It were used as a sample 20 entrepreneurs associated of AMIC, all participants of the project "The Development of a Support Program to Micro and Small Entrepreneurs in the Cities' Suburbs inside AMIC Scope" program that includes the University Without Borders: Extent Managerial Technology, developed in the classrooms of UNIOESTE - Campus Cascavel. The data were collected through site visits, interviews in the companies and application of questionnaires. It was found that most of the entrepreneurs, have little or no means of financial control, such as stock or cash flow. In general, they have an intermediate scholar-

\footnotetext{
1 Bolsista graduada em Administração - UNIOESTE - Endereço: Rua Maranhão, 1176 fundos. Bairro: Centro. CEP: $85801-050$ Telefone: (45) 99355891. E-mail: bruna.paese@gmail.com

2 Bolsista graduado em Bacharelado em Informática - UNIOESTE

3 Doutorando em Engenharia de Produção (UFSC) - Orientador do Projeto - UNIOESTE

4 Bolsista graduando em Informática - UNIOESTE

5 Bolsista graduando em Economia - UNIOESTE

6 Mestre em Engenharia de Produção (UFSC) - Coordenador do Projeto - UNIOESTE Financiadora do Projeto: Universidade Sem Fronteiras
} 
ity and are already in the market for a while. Keywords: financial management; entrepreneurship; education; technology; micro and small business.

\section{RESUMEN}

Este artículo tiene como objetivo identificar el perfil de los asociados de negocios de AMIC - Asociación de Micro y Pequeñas Empresas en Cascavel, haciendo hincapié en las formas en que estos empresarios trabajan con la gestión financiera de sus empresas. Se utilizó como una muestra de 20 empresarios asociados AMIC, los participantes del proyecto "El Desarrollo del Programa de Apoyo a las Micro y Pequeñas Empresas de la periferia de las ciudades de la AMIC cobertura" de la Universidad Sin Fronteras: extensión de Empresa de Tecnología, desarrollada en las aulas de UNIOESTE - Campus de Cascavel. Los datos fueron recolectados a través de visitas, entrevistas en las empresas y la aplicación de cuestionarios. Se constató que los empresarios, la mayoría de ellos tienen poco o ningún medio de control financiero, tales como la población o el flujo de caja. En general, tiene una escuela media y ahora son un buen momento en el mercado.

Palabras clave: gestión financiera, espíritu empresarial, educación, tecnología, micro y pequeñas empresas.

\section{Introdução}

Conforme Domingos apud Deitos (2002), a participação das pequenas e micro empresas é altamente significativa para a economia, representam, em quase todo o mundo, $90 \%$ do total de empreendimentos e contribuem em grande quantidade com a geração de empregos. Além de representarem uma alternativa viável e concreta para o fortalecimento da economia de um país.

Koteski (2004) relata os diferentes fatores que contribuem para a crescente participação desse tipo de empresa na economia brasileira. No Brasil, em termos estatísticos, esse segmento empresarial representa $25 \%$ do Produto Interno
Bruto (PIB), gera 14 milhões de empregos, ou seja, $60 \%$ do emprego formal no país, e constitui 99\% dos 6 milhões de estabelecimentos formais existentes, respondendo ainda por $99,8 \%$ das empresas que são criadas a cada ano, segundo dados do Serviço Brasileiro de Apoio às Micro e Pequenas empresas (SEBRAE).

De acordo com o estudo do Banco Nacional de Desenvolvimento Econômico e Social (BNDES), parte da proliferação dos pequenos empreendimentos é resultado da globalização, já que este fenômeno exige que grandes empresas, ao buscarem uma maior eficiência, terceirizam as atividades de apoio ao negócio principal, bem como a absorção de mão de obra demitida das grandes empresas em decorrência de avanços tecnológicos.

Nessas empresas foi constatado uma gradual redução nas taxas de mortalidade de micro e pequenos estabelecimentos e uma expressiva taxa de natalidade de micro negócios, através de estruturas flexíveis que permitem responder melhor $e$ mais rapidamente às crises econômicas. A exigência da modernidade requer empresas mais enxutas, menores e com maior índice de produtividade, alémdo espírito empreendedor do brasileiro - alguns dos fatores que contribuem para a evolução da microempresa (KOTESKI, 2004). O país está em sexto lugar entre os 31 países mais empreendedores do mundo, segundo pesquisa da Global Entrepreneurship Monitor (GEM)

As micro e pequenas empresas, também conhecidas como PMEs, possuem diferentes particularidades, tanto em relação às grandes empresas quanto aos diferentes ramos de atividade. Entretanto, essas empresas sofrem e compartilham dificuldades semelhantes entre si.

Segundo Gartner (1995) alguns instrumentos de análise econômico-financeira podem ser utilizados nesta fase da análise interna da empresa. Sendo eles a análise de índices de liquidez, atividade, rentabilidade e endividamento, o fluxo de caixa, o ponto de equilíbrio de custos e 
o grau de alavancagem. Os fatores tecnológicos devem ser analisados do ponto de vista de processo, produto e periférico. Este último se refere à aplicação de novos métodos à administração.

O trabalho tem como objetivo identificar o perfil dos empresários associados da AMIC, enfatizando as formas com que esses empresários trabalham com a administração financeira em suas empresas, criando assim ferramentas capazes de auxiliar os mesmos.

\section{Referencial teórico}

Importância da micro e pequena empresa.

Pequenas Empresas \& Grandes Negócios (2003). Apesar da injustiça social, o Brasil começa a mudar sua face neste início de século, estimulando a enorme capacidade criadora de sua gente, de seus trabalhadores. Um levantamento realizado pelo IBGE (Instituto Brasileiro de Geografia e Estatística), divulgado em setembro, constatou uma mudança radical no perfil do país. Hoje em dia, quando se leva em conta o universo das empresas com até 19 empregados (97\% do total de empresas do país), o número de sócios e proprietários tornou-se maior do que o de empregados no segmento - 5,7 milhões contra 5,4 milhões, respectivamente. "Em muitas microempresas, só existe o proprietário, e o escritório dele é o telefone celular", afirma Enio Pinto, gerente da Unidade de Educação e Desenvolvimento da Cultura Empreendedora do Sebrae. "Virei empresário na marra, para sobreviver", confessa Amadeu Portela da Rocha, 40 anos, um ex-catador de latinhas de cerveja que só estudou até a $4^{a}$ série e virou dono de uma empresa de reciclagem de materiais, a Reciclagem Ideal, no Distrito Federal.

Os novos empreendedores são quase sempre educados praticamente na rua, com pouco ou nenhum conhecimento sobre administração de empresas. Talvez por causa disso, as estatísticas apontem altos índices de mortalidade empresarial, embora estudos recentes tenham mostrado uma queda nesse indicador.

O Brasil é o país do mundo no qual mais gente se torna empreendedor por necessidade, de acordo com a pesquisa anual realizada pela Global Entrepreneurship Monitor (GEM) e coordenada por dois centros de referência mundial sobre empreendedorismo, o Babson College, dos Estados Unidos, e a London Business School, da Inglaterra. Os problemas das pequenas empresas, como dificuldades de acesso ao crédito, à tecnologia $e$ às compras governamentais e o despreparo na formação dos empreendedores, são proporcionais a sua importância econômica (PEQUENAS EMPRESAS \& GRANDES NEGÓCIOS, 2003).

\section{TABELA 1 - A SUPREMACIA DAS MICROS}

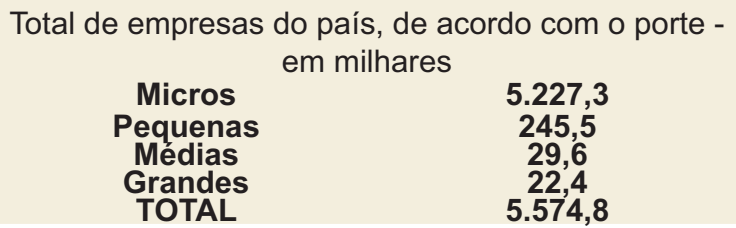

FONTE: PEQUENAS EMPRESAS \& GRANDES NEGÓCIOS (2003)

TABELA 2 - ELAS GERAM MAIS EMPREGO DO QUE AS GRANDES

Participação dos trabalhadores das micro e pequenas empresas no total de vagas no setor de comércio e serviços

$\begin{array}{ccc}\text { ANO } & \text { Micro e Pequenas } & \text { Médias e } \\ 1985 & 50,7 \% & \text { Grandes } \\ 1994 & 47 \% & 49,3 \% \\ 2001 & 60,8 \% & 53 \% \\ & & 39,2 \%\end{array}$

FONTE: PEQUENAS EMPRESAS \& GRANDES NEGÓCIOS (2003) 
Principais dificuldades encontradas pelas PMEs

Conforme Litenski e Lozeckyi (2006), embora as micro e pequenas empresas apresentem fatores importantes no crescimento da economia brasileira, bem como seu papel social na diminuição das desigualdades entre indivíduos e regiões, elas ainda encontram e enfrentam várias dificuldades para o exercício de suas atividades como: elevada taxa de mortalidade empresarial, embora o Brasil possua uma população empreendedora, por falta de preparo e apoio adequado, muitas vezes o brasileiro fracassa; falta de estrutura adequada em termos de aparato legal, contábil e gerencial; uma legislação tributária ainda desfavorável; muitas exigências burocráticas; carência de crédito e de uma política sistêmica de apoio $e$ incentivo às micro $e$ pequenas empresas.

\section{A contribuição do controle financeiros básicos na gestão de micro e pequenas empresas}

Para cuidar da gestão financeira, o empresário precisa lidar com números e informações o tempo todo. Se a empresa tem números confiáveis, ele consegue-as para tomar decisões. As informações financeiras de que precisa são obtidas por meio dos controles financeiros. A finalidade destes é gerar informações úteis e confiáveis para o empresário.

De acordo com pesquisas realizadas por Damian e Duarte (2008), são alguns dos controles utilizados pelas PMEs: o controle diário de caixa, que registra todas as entradas e saídas de dinheiro, além de apurar o saldo existente no caixa; o controle bancário, que é o registro diário de toda a movimentação bancária e do controle de saldos existentes; o controle de con- tas a receber, que tem como finalidade controlar os valores a receber, provenientes das vendas a prazo; o controle de contas a pagar, que organiza os totais a pagar obedecendo a seus períodos de vencimento: dia, semana, quinzena, e prazos (ex.: 30, 45, 60 dias); e o controle de estoques, que permite controlar os estoques existentes na empresa, evita desvios, fornece informações para reposição dos produtos vendidos e ainda, facilita a tomada de providências para redução dos produtos parados no estoque.

\section{Aplicação da tecnologia de informação na pequena empresa}

O custo cada vez menor dos computadores e a gestão integrada por software parecem incentivar cada vez mais o pequeno empresário a investir pesado nesse setor em busca de melhor desempenho da empresa com relação aos concorrentes. Esse tipo de investimento pode ser muito vantajoso para a empresa, porém poderá ser desastroso caso ela e os funcionários não estejam totalmente capacitados a lidar com essa nova tecnologia.

Segundo Prates (2003), a maior dificuldade encontrada na sua utilização da tecnologia da informação está relacionada à resistência por parte dos funcionários, indicando falta de treinamento e explicação prévios à implantação dos benefícios que seriam trazidos nas atividades rotineiras, levando, assim, tais funcionários a pensar que poderiam perder seus postos de trabalho para a TI.

Uma estratégia para as pequenas empresas que até o momento não tiveram contato com as novas tecnologias de informação, segundo Young apud Prates (2003), pode ser dividida em duas etapas:

a. familiarizar-se com a tecnologia de computadores, adquirindo um microcomputador que

Extensão em Foco, Curitiba, n. 7, p. 79-87, jan./jun. 2011. Editora UFPR 
possa ajudar com as funções não essenciais da empresa;

b. analisar as metas da empresa e suas esferas essenciais para aplicar tecnologias de informação, nas esferas essenciais dos resultados pretendidos.

Com o tempo, o pequeno empresário terá uma visão realista da maneira como os dados fluem na sua empresa e uma ideia aproximada de quais são as prioridades, analisando os impactos dos resultados sobre a produtividade. Não importa qual a tecnologia escolhida: ela deve ser flexível e adaptar-se ao desenvolvimento da organização.

A informatização pode trazer vários benefícios para a pequena empresa e, segundo o Sebrae, estas vantagens podem ser divididas em três grupos:

a. menores custos: quando bem utilizada, a informática pode agilizar alguns processos da empresa, simplificando rotinas burocráticas $e$ praticamente eliminando o retrabalho. Isso tudo faz com que custos sejam reduzidos;

b. maior produtividade: possibilita que as pessoas produzam mais em menos tempo, com menos gastos com recursos. Além disso, agiliza os processos de tomada de decisões em relação a preços, estoques, compras etc.;

c. maior qualidade: a qualidade dos produtos e serviços é melhorada, pois as tecnologias de informação ajudam a manter o padrão dos produtos dentro das especificações estabelecidas.

Uma empresa com um sistema totalmente informatizado, funcionando eficiente $e$ eficazmente, proporcionará grandes vantagens, seja em relação ao tempo otimizado, à organização, à facilidade de obtenção de informações, à previsão, e muitos outros aspectos que contribuirão para o sucesso da pequena empresa.

Dessa forma, a informatização das pequenas empresas possibilita que elas ganhem eficiência e eficácia melhorando, assim, sua competitividade e aumentando sua lucratividade.

\section{Metodologia}

\section{Descrição}

O trabalho é decorrente de um estudo realizado a partir da aplicação de um projeto de extensão que visa auxiliar as pequenas e micro empresas com deficiência na utilização de controles financeiros e softwares para gestão de suas empresas. Para isso o projeto disponibiliza cursos sobre controles financeiros básicos e palestras com assuntos pertinentes às empresas; outra fase do projeto é diagnosticar os processos financeiros e uso da informática nas empresas, em seguida é realizada uma visita técnica nas mesmas para poder prestar um apoio de consultoria para os empresários.

Para o diagnóstico foi aplicado um questionário, contendo cinco perguntas, visando apurar o procedimento adotado nos controles financeiros e a utilização de softwares e recursos tecnológicos, bem como as principais dificuldades encontradas na gestão financeira das empresas.

\section{Limitação}

A limitação encontrada é a de que no processo de seleção dos empresários para a primeira turma, realizada em Cascavel, não houve uma pré-seleção de empresas que necessitassem de conhecimentos básicos financeiros, processo este já corrigido para as próximas turmas, tornando assim o projeto dispensável para algumas empresas selecionadas, resultando em algumas desistências do curso.

\section{Análise e interpretação dos dados}

A avaliação $e$ análise dos resultados foram realizadas com a primeira turma de empresas do município de Cascavel. Para a amostra 
foram considerados 16 empresários de 15 empresas diferentes. A diferença entre o número de empresários e o número de empresas se justifica pelo fato de haver empresários da mesma empresa participando do curso.

Após a aplicação dos questionários, puderam-se obter informações importantes sobre os empresários e a realidade de suas empresas. De acordo com o nível de escolaridade dos empresários envolvidos, foi possível identificar que dos 16 entrevistados, 9 pessoas possuem ensino médio completo e apenas 2 entrevistados possuem superior completo.

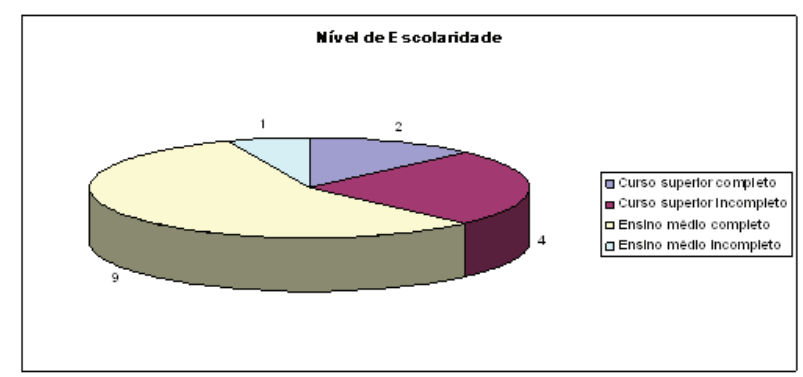

FIGURA 1 - NÍVEL DE ESCOLARIDADE DOS MICRO EMPRESÁRIOS FONTE: OS AUTORES (2009)

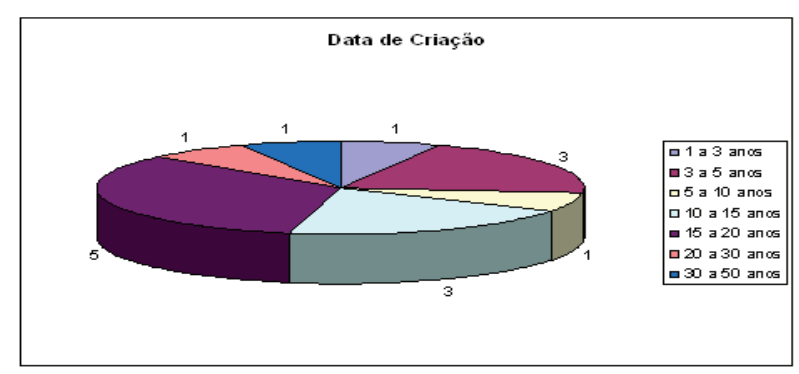

FIGURA 2 - IDADE DAS EMPRESAS SELECIONADAS FONTE: PESQUISA (2009)

Com relação à idade das empresas selecionadas, percebe-se que $73,33 \%$ possui mais de 5 anos, $e$ apenas $26,67 \%$ tem suas empresas abertas a menos de 5 anos. Das empresas entrevistadas, 8 possuem um quadro com até 10 empregados, 4 empresas, de 11 a 30 funcionários, e 3 empresas entre 31 e 50 funcionários.

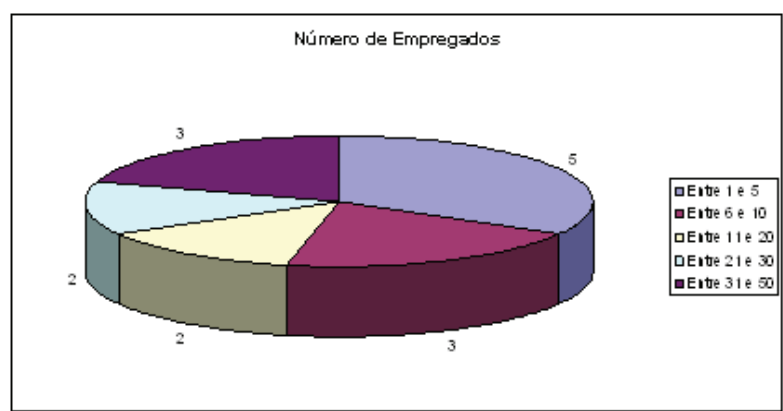

FIGURA 3 - NÚMERO DE EMPREGADOS NAS MICROEMPRESAS ENVOLVIDAS FONTE: PESQUISA (2009)

No que se diz respeito a controle de contas a pagar e a receber, aproximadamente $53 \%$ das empresas fazem seu controle manual, utilizando anotações em cadernos. Isto é uma grande preocupação, pois o empresário fica totalmente dependente de seu caderno, não possuindo controle que possa identificar possíveis alterações originadas de furtos, extravios, inadimplências, entre outros fatores que ocasionam perdas e até mesmo prejuízos financeiros as mesmas.

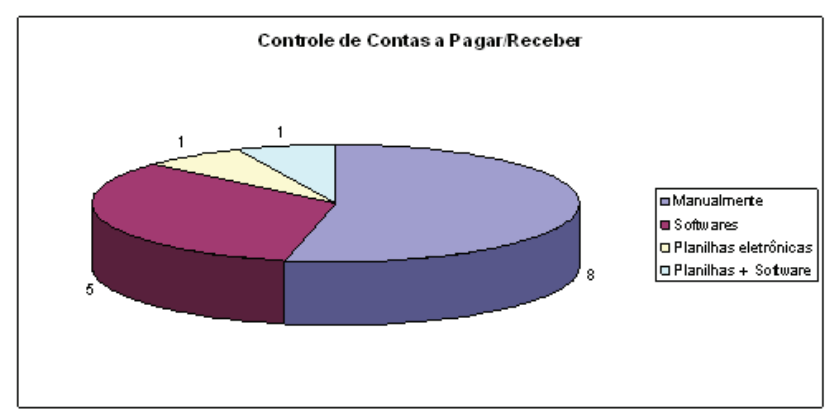

FIGURA 4 - FORMA DE CONTROLE DAS CONTAS A PAGAR E RECEBER DAS MICROEMPRESAS FONTE: PESQUISA (2009)

Após a observação de como as empresas controlam seus estoques, verificou-se que poucas fazem este controle de forma consistente. A maioria dos empresários realiza o controle de forma manual, acarretando muitas vezes em divergências entre o que tem no papel e o que tem realmente em seu estoque.

A Figura 5 ilustra as formas de controle de estoque realizado pelos microempresários que participam do curso. Em relação ao fluxo de caixa, 3 empresas não realizam esse controle e 6 
empresas realizam esse controle manualmente, utilizando-se de papel para projetar seu fluxo de caixa.

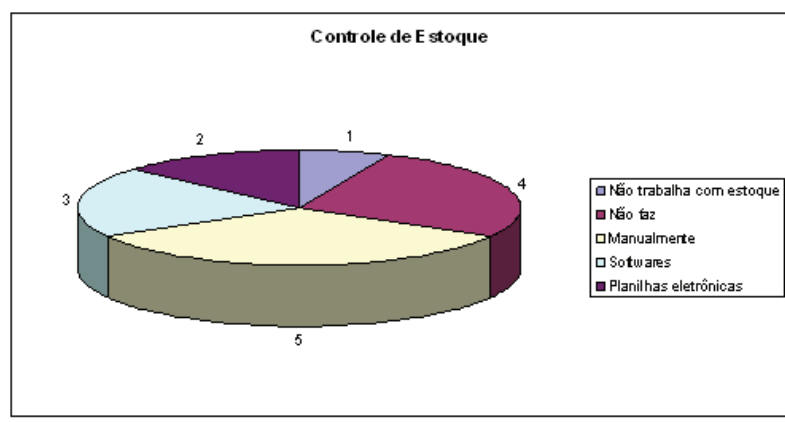

FIGURA 5 - CONTROLE DE ESTOQUES DAS MICROEMPRESAS FONTE: PESQUISA (2009)

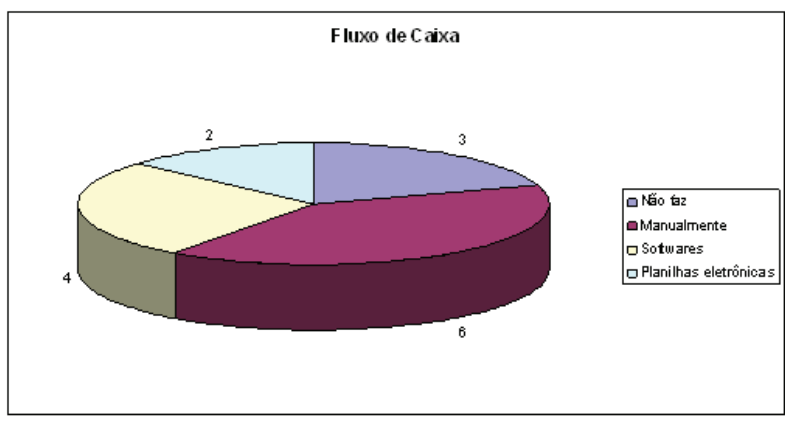

FIGURA 6 - FORMA DE CONTROLE DE FLUXO DE CAIXA FONTE: PESQUISA (2009)

Após as visitas a todas as empresas, foi realizada uma entrevista informal onde diagnosticou-se que todas as empresas não determinam o seu custo real, e a grande maioria dos empresários encontram dificuldades na área de Recursos Humanos, como a seleção de profissionais qualificados e a retenção de talentos.

Alguns empresários realizam seu controle financeiro manualmente, através de anotações em cadernos e livros de movimentação de caixa. Essa forma de controle pode fazer com que haja inconsistências e extravios de informações, visto que as informações são armazenadas em papel, e um possível furto ou erro de cálculo acarreta em perda de informações.
Foi possível realizar, através de consultoria para alguns empresários, a mudança desta forma manual de controle, onde pôde ser substituída por planilhas eletrônicas, que tornam as informações mais confiáveis, já que facilitam os cálculos, centralizando as informações e fazendo backups, sendo essa uma forma eficaz contra extravios e furtos.

Detectou-se também um grande número de empresários que não fazem distinção do caixa da empresa e suas retiradas pessoais, acarretando informações desencontradas no fechamento do mesmo.

\section{Conclusão}

Apesar das micro e pequenas empresas representarem a grande maioria das empresas brasileiras, observou-se que grande parte delas possuem deficiências na forma em que controlam suas finanças. Além de problemas nos controles financeiros, notou-se que pequenos empresários também possuem dificuldades em outras áreas da administração, como Marketing e Recursos Humanos.

Quanto à informatização, observou-se que a maioria delas possui acesso às tecnologias existentes, porém algumas não têm o hábito de alimentarem o sistema, fazendo com que a informática não traga benefícios para os controles financeiros das empresas. Com essas informações foi possível acrescentar alguns módulos no curso de controles financeiros básicos, como: um conteúdo que abrangesse a utilização dos recursos tecnológicos nas empresas; reforço no material de controles financeiros; proporcionar, aos participantes dos cursos realizados, palestras sobre marketing, recursos humanos e outras deficiências que possam sem encontradas e supridas. 


\section{REFERÊNCIAS}

DAMIAN, Ângela; DUARTE, Júlia. Gestão financeira de incubadoras. Out. 2008 Disponível em: <http:// www.secitec.mt.gov.br/TNX/storage/webdisco/2009/07/13/ outros/61c5449d616bcf8ee5bb3a50f8b67760.ppt\#25>. Acesso em: 23/07/2009.

DEITOS, Maria Lúcia Melo de Souza. A Gestão da tecnologia em pequenas e médias empresas: fatores limitantes e formas de superação. Cascavel: Edunioeste, 2002.

DESENVOLVIMENTO TECNOLÓGICO E INOVAÇÃO NAS MICROEMPRESAS E EMPRESAS DE PEQUENO PORTE. Características das ME e EPPs: Fatores que dificultam o acesso das ME e EPPs a recursos para desenvolvimento tecnológico e inovação. Nov. 2007. Disponível em: $<$ http://www.mdic.gov.br/arquivos/dwnl_1202923119. pdf $>$. Acesso em: 23/07/2009.

GARTNER, Ivan Ricardo. Análise de Projetos em Bancos de Desenvolvimento: Proposição de um Modelo de Análise. Florianópolis, 24 fev. 1995. Disponível em: <http://www.eps.ufsc.br/disserta/gartner/indice/index. htm\#indx>. Acesso em: 26/07/2009.

KOTESKI, Marcos Antonio. As micro e pequenas empresas no contexto econômico brasileiro. Mai. 2004. Disponível em: < http://www.fae.edu/publicacoes/pdf/revista_da_fae/ fae_v8_n1/rev_fae_v8_n1_03_koteski.pdf $>$. Acesso em: 23/07/2009.

LITENSKI, Mariane; LOZECKYI, Jéferson. Controles financeiros: um enfoque acerca das finanças empresariais. Set. 2006. Disponível em: <http://web03.unicentro. br/especializacao/Revista_Pos/P\%C3\%A1ginas/2\%20 Edi\%C3\%A7\%C3\%A3o/Aplicadas/PDF/10-Ed2_CSControl.pdf > . Acesso em: 23/07/2009.

MINISTÉRIO DO DESENVOLVIMENTO, INDÚSTRIA E COMÉRCIO EXTERIOR. Desenvolvimento Tecnológico e Inovação nas Microempresas e Empresas de Pequeno Porte. Nov. 2007. Disponível em: <http://www.mdic. gov.br/arquivos/dwnl_1202923119.pdf>. Acesso em: 23/07/2009.

ORLANDINI, L. A importância dos Sistemas de Informação - Administração e Tecnologia. Abril 2005. Disponível em <http://www.bonde.com.br/bonde. php?id_bonde=1-14--1646-20050407> . Acessado em: 28/07/2009.

PEQUENAS EMPRESAS \& GRANDES NEGÓCIOS. Brasileiro vira empreendedor. Nov. 2003. Disponível em: $<$ http://empresas.globo.com/Empresasenegocios/0,19125 ,ERA625674-2999-2,00.html >. Acesso em: 30/05/2009.

PEQUENAS EMPRESAS \& GRANDES NEGÓCIOS. Cresce $370 \%$ o uso de computadores nas MPEs. Dez. 2008. Disponível em: <http://empresas.globo.com/Emp
resasenegocios/0,19125,ERA1693575-2884,00.html . . Acesso em: 30/05/2009.

PRATES, Gláucia Aparecida. Inovação tecnológica através de sistemas de informação em pequenas empresas.Revista de Ciências Administrativas., Fortaleza, v. 9, n. 1, p. 4250, ago. 2003. 
APÊNDICE A - Questionário para avaliação inicial das empresas envolvidas no Projeto da AMIC 2009/2010

Data:

\section{Empresário}

Nome:

Data de Nascimento:

Telefone: E-mail:

Escolaridade: Área de Formação (se houver):

2. Empresa

Nome:

Endereço: Cidade:

Telefone: E-mail:

Bairro: Data de Criação:

Ramo de Atividade:

Número de empregados:

\section{Gestão empresarial}

3.1 Descreva os processos administrativos de acordo com a realidade da empresa:

a) É feito um controle de contas a pagar e a receber? Como é realizado?

b) A empresa realiza o controle de estoque? Como é feito?

c) É realizado um controle do fluxo de caixa? De que maneira?

d) A empresa utiliza alguma informatização (programa de computador, planilhas eletrônicas, entre outros) no controle financeiro da empresa?

3.2 Na gestão financeira da sua empresa, qual é a maior dificuldade que você encontra? 